\title{
Asystole, CTCAE 5.0
}

National Cancer Institute

\section{Source}

National Cancer Institute. Asystole, CT CAE 5.0. NCI Thesaurus. Code C146731.

A disorder characterized by a dysrhythmia without cardiac electrical activity. Typically, this

is accompanied by cessation of the pumping function of the heart. 